\title{
A Review of Eloisa May P. Hernandez's Digital Cinema in the Philippines 1999-2009
}

Katrina Ross Tan

Eloisa May P. Hernandez's Digital Cinema in the Philippines 1999-2009 is a welcome addition to a small body of work on Philippine film history. Few scholars venture on historical research on Philippine cinema primarily due to the difficulty in accessing primary data: lost films, poor state of archives, and unreliable anecdotal evidence (Grant, 2013). On the contrary, Hernandez has the advantage of having film and non-film sources available to build a history of contemporary digital cinema in the Philippines, and she has gathered it diligently to provide valuable information on the emergence and early development of digital cinema in the Philippines.

As stated in its preface, Digital Cinema is based on the author's dissertation "The Political Economy of Digital Cinema in the Philippines, 1999-2009” for her PhD in Philippine Studies. Prior to this, Hernandez's academic training is in Art History and Art Studies, and this is apparent in the present work and in her earlier ones, including a research on digital cinema in Southeast Asia funded by Southeast Asian Studies Regional Exchange Program, and a book on women visual artists in nineteenth century Philippines. It shows in how she carefully organized a swirl of data to construct a historical narrative from digital features she viewed, interviews she conducted, and documents she analyzed from her archival research. This is where her work as historian is strongest.

Digital Cinema is massive in scope as it sets out to "present the history and political economy of digital cinema in the Philippines from 1999 to 
May 2009" (Hernandez, 2014, p.1). The author later on stressed the fact that her work "evidently positions itself in technological film history" (p.11) but that "the history of digital cinema in the Philippines is examined through the prism of political economy" (p.12). I find it interesting to discuss technological history from political economy's frame. It would reveal that technology is not ideologically neutral and that access to it demonstrates a power struggle in which the capitalists usually dominates. But as the book reveals, technology can empower filmmakers because they can now own the means of producing a film. Making films using digital technology is relatively cheaper than using celluloid. The book argues that the introduction of digital technology resulted in shifts in the modes of production, distribution, and exhibition. To substantiate this claim, the author investigates on how digital films are produced, exhibited, and distributed in the Philippines. Moreover, Hernandez examines Filipino digital films' aesthetic tendencies and explores the notions of 'independence' in relation to digital cinema in the Philippines.

Aside from an introduction and conclusion, the book has two long chapters: Chapter 1 covers the history of digital cinema's first decade discussed in chronological order, and Chapter 2 contains discussion on its political economy. The first chapter is further divided into two periods: the period of introduction and the period of innovation (p.12). On the other hand, the second chapter is broken down into discussing digital cinema's modes of production, distribution, and exhibition. This chapter also discusses the notion of 'independence' in digital cinema in the Philippines. While this organization clearly delineates the history of digital cinema from an analysis of its political economy, the historical narrative could have already been presented through the political economy frame. In this sense, the historian can guide the readers on how to interpret the historical data presented.

Nonetheless, the work is undeniably important in providing baseline historical facts on digital cinema's technological history found in the first chapter. The data from her interviews of filmmakers, film programmers, and producers provide a gold mine of facts and insights not only on digital technology's introduction in local filmmaking, but notably on producing a film outside the commercial system. For example, the interviews on digital filmmaking pioneers Jon Red, Khavn dela Cruz, Ed Lejano, Ellen OngkekoMarfil, John Torres, Raya Martin and Lav Diaz allow the readers to pick their artistic minds. Similarly, insights of Ed Cabagnot, founder of Cultural Center of the Philippines' Sineklab, Freefest Film Festival and programmer in Cinemalaya, and other festival organizers demonstrate the crucial role of other stakeholders at the back of the camera and the movie screen to 
create exhibition venues for digital films. Documenting these oral histories reinforces the significance of Hernandez's work in Philippine cinema history.

The second chapter, "Political Economy of Digital Cinema in the Philippines," synthesizes the data presented in the preceding chapter to arrive at a discussion of the various modes of production, exhibition, and distribution the author formulated. Hernandez proposes the following modes of production practiced by digital filmmakers in the Philippines: (1) selfproductions; (2) artist-run productions; (3) industry-based independents; and (4) mainstream film companies, media conglomerates/network-based companies (p.147). The case examples presented illustrate such modes and provide indispensable data in constructing a broader historiography of contemporary Philippine cinema.

Additionally, it is notable for Hernandez to identify mainstream film companies as part of digital cinema since the latter has come to be associated with independent cinema (p. 219). She comments that of all digital cinema's modes of production, commercial media and film companies "offer the least space for filmmakers for aesthetic experimentation" (p.191). Conversely, the other three modes allow digital filmmakers to experiment on the new medium as revealed in her discussions. One example she cited is John Torres' Todo Todo Teros, where stock footages and staged footages were combined in a film. This defies the notion that only staged action is acceptable in film. Another is Lav Diaz's long films-Ebolusyon ng Pamilyang Pilipino (2004), Heremias (2006), and Death in the Land of Encantos (Kagadanan sa Banwaan ning mga Engkanto, 2007) - that defy commercial imperative of having lessthan-three-hour feature film. The author categorizes Torres and Diaz's films under self-productions and, as such, the directors have full artistic control over their films. As Hernandez has noted, such experimentations are highly unlikely to be accommodated in commercial filmmaking.

Because of this belief, it is understandable for her to find Cinema One Originals' production of Sherad Sanchez's Huling Balyan ng Buhi (2006) 'admirable." She said,

[i]t is admirable that a film such as Huling Balyan $n g$ Buhi and its uncommercial subject was produced by ABS-CBN's Cinema One. It illustrates the fact that with projects that require less financing, even a media conglomerate can be more flexible with the kind of film projects they support. They give more leeway to the filmmaker to choose their stories and not be limited to the more commercial subject matters. (p.97) 
While there may be truth to this claim, I find it disagreeable to 'admire' the effort of the media conglomerate in producing 'uncommercial subjects' because, as an analysis of political economy would reveal, commercial producers would not take such a big risk without any assurance of profit, even if it is not immediate. Since the book is supposedly informed by theories on political economy, the discussion could have revealed how low-cost digital filmmaking with 'uncommercial subject' can benefit commercial media as well in the long run. Although commercial producers know that these films will not earn in the box-office, they know that it can earn someplace else. ABS-CBN, for example, has the Cinema One cable channel, and the rationale for Cinema One Originals is precisely to generate content for the latter. Hence, these low-budget, high-quality digital films can be distributed in cable television where the media company can generate income from advertisements. While it is good that filmmakers are given opportunities to make their films with greater control, commercial producers ultimately benefit more in this context because they are able to produce high-quality films at a very low cost. Since the film rights belong to the mainstream company and not the filmmakers, as in the case in Cinema One Originals, the former has full control on how to distribute the film. The book could have extended the discussion of digital cinema's political economy to account for such configurations. None the less, Hernandez has pointed out that "mainstream producers have co-opted and appropriated digital technology for their won commercial ends" (p.192), citing sex-drama and gay films as examples of such kinds of productions.

Chapter Two of Digital Cinema additionally covers digital films' modes of distribution and exhibition. Hernandez has stated that digital filmmakers experience difficulty in bringing their work to a wider audience. She explains that digital films often do not reach commercial theaters because at that time commercial theaters were not yet equipped with digital projectors. Moreover, she points out that independent filmmakers face more difficulty distributing their films since they do not have additional funding to market their films. As a result, they rely on film festivals to showcase their works (Hernandez, 2014). Aside from film festivals, Hernandez identifies TV broadcast and cable release, international film festivals, video distribution (including self-made DVDs), the Internet, and even mobile phones as distribution routes of digital films (197-204).

In terms of exhibition, Hernandez cites alternative screening venues for digital films, particularly those made independently. These include the Mowelfund Film Institute, University of the Philippines Film Institute, the Cultural Center of the Philippines, the National Commission for Culture and the Arts (NCCA), and in smaller venues, such as restaurants, cafes, and bars 
(205-207). Moreover, commercial theaters have screened few digital films. Here the author mentions the early attempt at distributing independent films in commercial theater with Robinsons Indie Sine. However, it eventually closed shop because independent digital films did not meet sales quota. In her discussion, Hernandez mentions commercially successful digital films, and this is probably one of the reasons that she remained convinced that conventional theatrical release is the recommended mode for digital film distribution. But while digital technology altered ways of production and, to some extent, exhibition, it has not done so in terms of distribution. As discussed in the book, digital films needed to be blown up to $35 \mathrm{~mm}$ to be screened in commercial theaters (195). This seems like a practical matter, but looking closely, it is symbolic of capitalists' stronghold in the film industry. The commercial system of distribution and exhibition is solidly in place, where they prefer entertainment films that attract mass audience. A new player in the form of 'serious' independent films would find it difficult-if not impossible - to penetrate commercial theatrical distribution at this point. If the book's discussion were extended to the broader political economy of film distribution in the country, the author could have identified the nearimpossibility of commercially distributing independent digital films.

In the same chapter, the author's examination of 'independence' in digital cinema provides insightful discussion, but her voice could not be clearly heard amidst the strong voices of Philippine independent cinema pioneers. It is useful to read discourses on "independence" in different period in Philippine film history, but a more sustained theoretical engagement on the author's part on what 'independence' might mean in digital cinema could have enriched the book's argument. This is also where the author could have problematized the notion of 'independence' when mainstream producers make digital films, such as in the case of Cinema One Originals and, to some extent, Cinemalaya.

As the scope of the book entails a survey of digital film productions in the Philippines, it is noteworthy that Digital Cinema mentions examples of regional films. However, only those that were shown in Metro Manila were included due to the methodology used. Using a few examples, such as Joenar Pueblo's Dagyang: An Ilonggo Story (2007) and the regional films that were nominated in Gawad Urian, Hernandez argues on the opportunities provided by digital technology for regional filmmakers: "[d]igital technology also ushered a renewed interest in filmmaking among filmmakers in the region" (p.116). She also cites Cinema Rehiyon, the national festival of regional (digital) films established by NCCA, in her discussion of digital film's modes of exhibition (p.133). It is noticeable, however, that the author has more substantial discussions on Manila-based digital film productions and 
festivals. Her work could have demonstrated the extent of 'digital revolution' in the country and could have strengthened her claim on democratization of filmmaking by discussing as well how digital technology was introduced and used innovatively in the capital's peripheries. Presumably, the author's proximity to the primary data and interviewees made her prefer to focus on digital films in Metro Manila. However, expanding the discussion to regional filmmaking could substantiate further Philippine digital cinema's history that is not Manila-centric.

The book's argument presumes that an introduction of technology creates change in how things are done. Although it is partly true that digital technology changed the landscape of filmmaking in the Philippines, technology itself is not the only and primary force that introduced these changes but, more significantly, the individuals themselves who adopted the technology and experimented on its usefulness in filmmaking. This is made clear in the data presented in the book. Hernandez has documented the innovations done by independent filmmakers on digital technology, as well as the efforts of festival organizers, producers, institutions, educators, scholars, and the audience in the development of digital cinema. Given this, the role of digital technology in the blossoming of digital cinema should be de-emphasized and the people who have contributed in building digital cinema should be given main credit instead.

In summary, the book provides a comprehensive documentation of the emergence and development of digital cinema in the country, albeit centered mostly in the capital. It provides important historical data on the modes of production, exhibition and distribution of digital cinema at the turn of the 21st century for its intended readers, such as students and scholars of Philippine cinema. Scholars working on digital cinema in general would find this work useful as it contains oral histories from various players in digital filmmaking. Moreover, the appendix of full-length digital films from 1999 to 2009 with release dates is most helpful to illustrate the surge of filmmaking that revived the ailing film industry. Minor errors can be found in the footnote numbering system though it does not devalue the book's worthy contribution. While expanding the discussion to regional digital films could have provided a more substantial view of digital technology's extent and reach in filmmaking, and while the analysis of political economy of digital cinema in the Philippines beyond descriptive level could have revealed complex power relations in the film industry and in independent cinema, the book is none the less a significant work in contemporary Philippine film history. 


\section{Reference}

Grant, P.D. (2013). Ang pelikulang Binisaya Cebuano film and the search for a regional cinematic heritage. Film International, 11 (F0020003), 73-82.

Hernandez, E. M. P. (2014). Digital cinema in the Philippines 1999-2009. Quezon City: University of the Philippines Press.

KATRINA ROSS TAN is an assistant professor in the Department of Humanities in University of the Philippines Los Banos. She is a film festival organizer and programmer, and she has served as a member of the Cinema Committee of the National Commission for Culture and the Arts (NCCA) from 2013 to 2016. She is currently on study leave pursuing her PhD in Film, Media and Communication in Monash University in Australia (corresponding author:katrinarosstan@gmail.com). 
